\title{
The challenge of communication in interpreted consultations in diabetes care:
}

\author{
a mixed methods study
}

\begin{abstract}
\section{Background}

The experience of diabetes care for individuals from minority ethnic groups, particularly individuals of Bangladeshi origin, shows they are at a significant disadvantage.

\section{Aim}

To identify the challenges of interpreted consultations for healthcare providers and to explain the disadvantage experienced by patients from minority groups who have diabetes.

\section{Design and setting}

Comparison of 12 interpreted consultations with 24 consultations involving fluent English speakers in four primary healthcare centres in Tower Hamlets, east London, UK.
\end{abstract}

\section{Method}

Content analysis of video recordings of routine diabetes review consultations in primary care, involving 36 patients, nine nurses or healthcare assistants, and six interpreters.

\section{Results}

Interpreted consultations were as long as samelanguage consultations but patients said less. The incidence of misunderstandings was similar but patients in interpreted consultations asked fewer questions. Indicators of social distance in interpreted consultations included less humour and less discussion of the patient's feelings or personal circumstances. Patients in interpreted consultations were less likely to raise issues unrelated to diabetes, to discuss their own ideas about health, or to talk about clinical parameters. Providers commonly addressed Englishspeaking patients directly but usually addressed patients through interpreters using the third person. Interpreters sometimes changed the meaning or did not translate speech, and they added their own comments.

\section{Conclusion}

The findings explain some of the known problems of diabetes care for individuals from ethnic minorities. Effective training for interpreters and care providers is needed to reduce social distance and to facilitate patients involvement in self-management.

\section{Keywords}

communication; diabetes mellitus; ethnic groups; multilingualism; primary health care.

\section{INTRODUCTION}

In 2012, diabetes was estimated to affect 3.1 million individuals in the UK and to consume $4 \%$ of the NHS budget. ${ }^{1}$ Individuals from minority ethnic communities are five times more likely than others to have type 2 diabetes. ${ }^{2}$ In east London, where this study was carried out, the prevalence of type 2 diabetes has been found to be 3.5\% for white individuals, $11 \%$ for South Asian individuals, and $8 \%$ for black individuals. ${ }^{3}$

National audits of care show geographical variability in carrying out nine crucial tests at annual diabetes review: 4,5 measurements of weight, blood pressure, smoking status, glycosylated haemoglobin ( $\mathrm{HbA1c}$ ), urinary albumin, serum creatinine, and cholesterol, and secondary damage to the eyes and feet. There is also variability across ethnic groups. Among those with type 2 diabetes, white patients have been shown to be more likely than other ethnic groups to have completed all of these care processes. ${ }^{5}$ Encouraging self-management of diabetes is an important priority for care providers, and an important part of diabetes review is to inform and motivate patients in this task. ${ }^{6}$

Although community leaders may disagree, ${ }^{7}$ some evidence suggests poorer awareness of diabetes and its complications in minority ethnic communities. ${ }^{8}$ In one study, individuals of Pakistani and South Asian origin living in Edinburgh were found to be more likely to blame their external environment than themselves for their diabetes. ${ }^{9}$ Chronic kidney disease in black

C Seale, BEd, MSc, PhD, professor of sociology, Department of Sociology and Communications, Brunel University, Uxbridge. C Rivas, BSc, MSc, $\mathrm{PhD}$, research fellow; M Kelly, BSc, RMN, MA, $\mathrm{PhD}$, senior lecturer in medical sociology, Centre for Primary Care and Public Health, Barts and the London School of Medicine and Dentistry, Queen Mary University of London.

\section{Address for correspondence}

Clive Seale, Department of Sociology and Communications, Brunel University, Uxbridge, and South Asian patients with diabetes is more severe than in white patients, whose glycaemic control is also better. ${ }^{3}$

Dissatisfaction with diabetes care among patients and others of Bangladeshi origin has been found in studies in Bradford, ${ }^{10}$ Cardiff,11 and east London. ${ }^{7}$ Frustration by healthcare providers is also reported in these studies. Socioeconomic and educational differences that are associated with ethnicity may explain some of the differences in experiences of care, but it is clear that much of this difficulty stems from communication problems where different languages are involved. Responders in the study of east London specifically cite difficulties experienced in consultations involving interpreters, ${ }^{7}$ and there is some evidence that patients' presentation of themselves as knowledgeable, morally responsible individuals is more difficult when patients and providers do not share the same language. ${ }^{12-14}$

With over 300 languages spoken in London alone and an estimated 300000 individuals in the UK without functional English to permit communication with a health service provider, ${ }^{15}$ it is unsurprising that provision of professional interpreter services in the NHS is both common and costly. ${ }^{16}$ Yet there have been no significant published studies involving direct observation of interpreted consultations in the UK, although some work of this sort has been done on consultations with UK patients for whom English is a second language. ${ }^{17,18}$

Middlesex, UB8 3PH, UK

E-mail: clive.sealeabrunel.ac.uk

Submitted: 10 August 2012; Editor's response: 25 September 2012; final acceptance: 5 October 2012.

\section{CBritish Journal of General Practice}

This is the full-length article (published online 28 Jan 2013) of an abridged version published in print. Cite this article as: Br J Gen Pract 2013; DOI: 10.3399/bjgp13X663082 


\section{How this fits in}

There are ethnic variations in the quality of diabetes care and satisfaction with diabetes care in the UK, with South Asian patients being particularly likely to report disadvantage. Studies of interpreted consultations outside the UK have identified a number of challenges that these pose. This study found that interpreted consultations for diabetes care differ from similar same-language consultations, with greater social distance between the care provider and patient and less involvement of patients in discussing clinical indicators. Effective training for interpreters and those working with them is needed to facilitate non-Englishspeaking patients' involvement in selfmanaging their condition

This contrasts with research from the US and elsewhere, which provides some evidence about common difficulties in communicating through interpreters. Much of this work involves Hispanic speakers in the US, the relevance of which for other settings and cultures is unknown. Such studies have found that interpreted consultations, when compared with samelanguage encounters, involve less affective talk, less discussion of the patient's personal circumstances or 'lifeworlds', and less investigation by providers of patients' knowledge or health beliefs. ${ }^{19-21}$ Patients in interpreted consultations are often less active, asking fewer questions, 19,21,22 and interpreters have sometimes been found to either answer patients' questions themselves without translating them, or fail to translate or answer them. ${ }^{12,22}$ Errors, omissions, misunderstandings, and inaccuracies in translation have been documented, particularly where informal rather than professional interpreters are used. ${ }^{12,13,19,23,24}$ Health service providers commonly do not address the patient directly, instead address the interpreter, ${ }^{25}$ and professional interpreters commonly take on the role of 'co-diagnosticians', aligning themselves with the perspectives of healthcare providers rather than patients. ${ }^{12,20,26}$ Providing extra time for interpreted consultations, splitting talk up so that it is delivered in smaller chunks, and frequently checking understanding has been recommended. ${ }^{27,28}$

This article reports data from the first study in the UK involving direct observation of interpreted consultations, comparing these with same-language consultations.
The research studied routine review consultations for diabetes care, largely carried out by nurses in primary care settings, occurring in east London where a significant proportion of the population land of those with diabetes) is of Bangladeshi origin. Content analysis of video-recorded consultations is used to provide insight into the challenges they present and the relevance of recommendations on how to work with interpreters in a UK context. ${ }^{27,28}$

\section{METHOD}

This is an analysis of a subset of data from a larger collection of 57 video- and audiorecorded consultations with patients receiving diabetes care in primary care settings in London in 2010-2011. This article considers 36 consultations occurring within the London borough of Tower Hamlets, excluding consultations where the patient was not fluent in English but did not require an interpreter. The aim of the study is to compare interpreted with fluent samelanguage consultations. In Tower Hamlets, 148 adult patients with diabetes, with appointments mostly for routine review meetings with nurses or healthcare assistants in four practices, were invited to take part. Twenty-eight percent (41/148) did not attend their appointment; 49 of 107 attenders (46\%) agreed to participate and filled in a brief form in which they were asked to indicate their demographic data, including ethnicity. Nurses, interpreters, and other providers of care were separately informed of the study and consented to take part, with written consent being obtained for all those directly involved.

English-language recordings were transcribed in English by a professional transcriber. Where a language other than English was involved, a translator and one of the research team viewed and listened to the audio and video recordings together. The translator verbalised in English the non-English passages, which were sometimes replayed several times. This translated talk was itself audiorecorded and then transcribed and added in italics to the English transcripts.

A coding scheme (Table 1) for content analysis was developed by all three researchers and applied to the transcripts by two of the researchers, using NVivo9 software. They independently coded groups of four transcripts at a time, discussing any discrepancies and refining coding definitions until an acceptable Cohen's kappa statistic measuring inter-rater reliability was achieved for all codes (the final overall kappa was 0.84). Codes were 


\section{Table 1. Coding scheme for categorising the utterances of speakers}

\begin{tabular}{|c|c|}
\hline Code & Definition \\
\hline Misunderstanding & Not understanding another speaker, plus repairs of misunderstanding \\
\hline Check understanding & $\begin{array}{l}\text { Checking another speaker has understood, or asking for clarification of } \\
\text { what has been said }\end{array}$ \\
\hline Questions & Questions (excludes rhetorical questions) \\
\hline Health education & $\begin{array}{l}\text { Advisory information about diabetes and diabetes care (patients' } \\
\text { speech excluded) }\end{array}$ \\
\hline Motivation & $\begin{array}{l}\text { Patient's motivation or willpower to engage in self-care or change } \\
\text { health-related behaviour }\end{array}$ \\
\hline Praise & Praising the other person for health-related actions or knowledge \\
\hline Patworld & Any speech coded at any of the four codes below \\
\hline 1. Humour & Humorous moments, laughter, light-hearted banter \\
\hline 2. Lifeworld & $\begin{array}{l}\text { Social chit chat, personal context of the patient, their family, or friends. } \\
\text { Mention of special events such as Ramadan or birthdays outside the } \\
\text { health and social care system }\end{array}$ \\
\hline 3. Feelings & $\begin{array}{l}\text { Reports of, or questions about, emotional states. Emotionally } \\
\text { expressive interjections }\end{array}$ \\
\hline 4. Employment & Patient's employment, work or job-seeking efforts \\
\hline All clinical & $\begin{array}{l}\text { Any speech coded at any of the } 14 \text { codes below lall of which are for } \\
\text { diabetes-related talk only) }\end{array}$ \\
\hline 1. Blood tests & Blood tests \\
\hline 2. $\mathrm{BP}$ & Blood pressure \\
\hline 3. Cholesterol & Cholesterol \\
\hline 4. Exercise & Exercise \\
\hline 5. Eyes & Eyes and eye checks \\
\hline 6. Feet & Feet and foot checks \\
\hline 7. Flu & Flu vaccine \\
\hline 8. Food & Food and diet \\
\hline 9. Kidney & Kidney and kidney complications \\
\hline 10. Medications & Medications and how to use them \\
\hline 11. Smoke & Smoking \\
\hline 12. Sugar and $\mathrm{HbA} 1 \mathrm{c}$ & Sugar/HbA1c levels \\
\hline 13. Urine test & Urine tests \\
\hline 14. Weight & Weight, BMI \\
\hline Medical other & Medical or health problems unrelated to diabetes \\
\hline \multicolumn{2}{|l|}{ Patient's speech only } \\
\hline PClinPar & $\begin{array}{l}\text { Patient evaluates or gives information about how they are doing on } \\
\text { diabetes-related clinical parameters (such as those included under 'All } \\
\text { clinical'), excluding talk about health behaviour or behaviour change }\end{array}$ \\
\hline Epistemic & $\begin{array}{l}\text { Patient's knowledge, beliefs, or ideas about the workings of their body } \\
\text { or health/illness. This includes material sometimes called 'lay health } \\
\text { beliefs' and includes expressions of not knowing enough, or much, } \\
\text { about these things }\end{array}$ \\
\hline \multicolumn{2}{|c|}{ Interpreted consultations only } \\
\hline Meaning changed & $\begin{array}{l}\text { Where attempted translations change the meaning of what was said in } \\
\text { the other language }\end{array}$ \\
\hline Talk not translated & Significant messages that are not translated \\
\hline Other than translated & $\begin{array}{l}\text { Any interpreter speech that is not an attempted translation of what } \\
\text { another speaker has said }\end{array}$ \\
\hline
\end{tabular}

$B M I=$ body mass index $. B P=$ blood pressure. $H b A 1 c=$ glycosylated haemoglobin. Patworld = patient world. PClinPar= patient clinical parameters.

applied to whole paragraphs only, with each paragraph representing a turn-at-talking by a speaker. Boxes 1 and 2 show examples of talk coded under selected codes.

Of 12 consultations that involved interpreters, 10 involved patients of Bangladeshi origin, the other two being with a (Jordanian) Arabic speaker and an Urdu speaker lwhose first language was Pashto). The rest involved patients with varying degrees of fluency in English. In this article, the 12 interpreted consultations are compared with 24 consultations with patients whose English was judged 


\section{Box 1. Examples of selected codes (non-English speech in italics)}

\section{Interpreted}

\section{Misunderstanding}

Language Line (LL): 'You don't want to smoke or do you still want to carry on smoking?' P: 'lam smoking cigarettes.

LL: 'Do you want to leave it now or carry on?

P: 'l'm keen to stop.'

LL: 'They can help you quit smoking if you want to.'

P: 'What thing is that?'

LL: 'They can help you if you want to quit smoking.

(Patient 35)

\section{Health education}

Interpreter (I): 'The main problem with Bengali people is that when we walk we don't walk fast enough. When you walk fast your heart beats faster, you sweat, you feel

tired, and that is exercise. We people - we walk but we walk at such a slow pace it

does not do anything for us.

(Patient 42)

\section{Motivation}

P: OK my dear I am doing whatever they asked me to do. They gave tablets, I am having the tablets.

(Patient 8)

Praise

$\mathrm{N}$ : 'OK. That's good. So it's really important that she keeps that up.'

(Patient 8)

\section{Humour}

P: 'I take medications without knowing their names [laughs].

(Patient 46)

\section{Lifeworld}

$\mathrm{N}$ : 'I know she doesn't read English, but possibly her family will be able to explain it to her.

I: 'You have people at home that know English, your children can

read English?

P: 'Yes.'

(Patient 8)

\section{Feelings}

$\mathrm{N}$ : 'And she's lost weight from doing it, so that's fantastic!'

I: 'She is saying it's good that you are doing it.'

P: 'Yes it's for my benefit not for her.

I: 'For her there's benefits.'

(Patient 8)

\section{Medical other}

P: 'But my this, for this I can't sleep all night.

I: 'Today she will not talk about this, today is for diabetes.

P: 'Every few moments inside my throat this happens all night, inside it itches,

its not that big doctor gave I had, it itches and does khek khek, it is embarrassing in front of people.

$\mathrm{N}$ : 'How does she feel about that?

I: 'She said it's not a problem, and she's talking about her other, er

dyspepsia her symptoms.'

$\mathrm{N}$ : 'OK. Not related to diabetes?

I: "No.'

N: 'No? OK. All right.

(Patient 8)

\section{Patient clinical parameters}

P: 'My wife doesn't know how to use the machine. If it's low / can tell its low.

I can't walk, I sweat and shake.

(Patient 12)

\section{Epistemic}

$\mathrm{N}$ : What does she understand that diabetes is?

I: What do you understand that diabetes is? What is diabetes?

P: 'I don't understand any of this.

I: 'But your husband had diabetes. Do you understand it? Do you

understand what diabetes is? Can you tell me?

P. "No.

I: 'No, she can't tell.'

(Patient 11)

\section{English}

Patient (P): '[pause] blood sugar?

Nurse (N): 'Blood pressure.'

P: 'Blood pressure, sorry.'

(Patient 41)

$\mathrm{N}$ : 'Well, it is important to eat regularly, you know, even if it's a small amount. And you're happy with, you know, you have a small amount, 'cos obviously not having food will only cause more problems. (Patient 45)

P: 'Yeah, I really want to do it, it just always seems to be that I can, I can never get a minute.

(Patient 43)

$\mathrm{N}$ : 'So that's doing extremely well; it was six point four, okay, which is fantastic.'

P: 'Oh, that's the best l've ever had!'

$\mathrm{N}$ : 'Yeah? That's amazing. So you've done really well.'

(Patient 2)

P: 'So l'll be getting those Viagra put on my next prescription?

$\mathrm{N}$ : 'I've given you them there.

[...]

P: 'Yeah, my girlfriend will be happy.

$\mathrm{N}:$ 'Sorry?'

P: [chuckles]

N: 'Good, OK. Well, let's hope you are as well [laughter].'

(Patient 41)

P: 'I played golf Sunday I couldn't find my golf shoes so I bought a new pair.

(Patient 19)

P: 'I don't know [pause] you know? I wish I could just, erm [pause] I wish I could just forget it, but I can't!'

(Patient 6)

P: 'Talking about the arthritis'

$\mathrm{N}: \mathrm{Mmn}$ ?

P: 'I'm on ibuprofen and co-codamol, right?'

$\mathrm{N}:$ 'Mmn.'

P: 'When I used to take one it'd be fine, it' $d$ kill the pain.'

N: 'Right.'

P: 'Right? But now l'm finding I need to take more and more.'

$\mathrm{N}$ : 'OK.

P: 'And mixing the two, I'm a bit worried about it.'

(Patient 2)

P: 'Alright, it's gone, to be honest with you, it's gone really well. You know it's erm, gone down really well and the weight's coming off and you know l'm trying everything [laughs].

(Patient 34)

P: 'Well, I [pause] er [pause] sometimes have pains in my lower intestine. N: 'Mhm.'

P: Which I understand may be caused by the metformin or the simvastatin, or perhaps by both [pause].'

$\mathrm{N}$ : 'Mhm, mhm.

P: 'But they're not severe enough to make me want to change things.' (Patient 23) 


\section{Box 2. Extracts from interpreted consultations (non-English speech shown in italics)}

\author{
Interpreter changes the meaning of what was said \\ Patient (P): 'Yes / do understand. \\ Interpreter (I): 'Confused, yeah ... that's what he said.' \\ (Patient 13)
}

Nurse: 'So, shall we check her blood pressure now? Just see how that is?

I: 'She will check your blood pressure.

(Patient 8)

P: "I want to control everything, but / am not able to do so.

I: 'So she's saying she would like to you control both her [pause] um, focus on both the weight and the

cholesterol.

(Patient 42)

\section{Talk not translated by the interpreter}

P: 'She [nurse] does so much but I don't believe anything is helping.

(Patient 42)

P: Eight ten teeth are falling out.

I: 'Why are your teeth falling out?

P: 'I don't know they just fell out quick.

I: 'What's happening to your eyes?

P: 'I don't know I can't see, I can't see close up. When I put my glasses on I can't see.

(Patient 27)

\section{'Other' than translated speech}

Daughter lacting as interpreter): 'So we're like willing to like get some time for that, because we both enjoy swimming and that's like it's quite effective in terms of losing weight!

(Patient 26)

I: 'These small changes if you make them, you should still make them and it will be good. For example, you are telling me that you do regular exercise but then you eat a bit too much and you also have your biscuits and croissants. If you do this, you will see no results. So that's why you can't just do one thing, you have to look at it all round and then you'll see your result.

(Patient 42) consultation in English. Six interpreters were involved, one of whom communicated by phone link ('Language Line'). All but one of the interpreted consultations (where an adult daughter interpreted) involved a professional interpreter who shared the ethnic origin and language of the patient, with the exception of the Pashto speaker, where the interpreter had Urdu as a first language and the patient was speaking Urdu as a second language.

Quantitative analysis was carried out using SPSS (version 16), with exported NVivo9 spreadsheets indicating the number of words coded under each coding theme. Supplementary analysis of word distributions was carried out using Wordsmith Tools (version 5.0), software developed for computational linguistics and used in keyword analysis.

\section{RESULTS}

Table 2 shows that, although there was no significant difference in the time taken by interpreted and same-language consultations, patients who spoke English produced 3.6 times the number of words produced by patients in interpreted consultations.

Table 3 demonstrates that, while patients' misunderstanding and their attempts to check understanding were not significantly different across the two groups, patients in same-language consultations were more likely to produce utterances that included questions or that involved discussion of health education or of their own motivation to engage in health-related behaviour, and to participate in praise for health-related actions or knowledge. With the exception of employment, all of the patient world 'patworld' codes (Table 1) more frequently applied to patient speech in same-language consultations, with more humorous moments and discussions of feelings and of 'lifeworld' topics, as defined by the researchers (Table 1). A number of diabetesrelated clinical topics were discussed more in same-language consultations. Patients in interpreted consultations devoted less speech to medical issues unrelated to diabetes ('medical other') and there was less talk about patients' own ideas about the workings of their bodies or of health and illness ('epistemic'), as well as less patient involvement in evaluating or informing about diabetes-related clinical parameters (patient clinical parameters) (Table 1).

Table 4 shows that providers were more likely to produce utterances containing humour and to talk about feelings with their English-language patients, so that 
Table 3. Number of words coded (patients' words only) ${ }^{a}$

\begin{tabular}{|c|c|c|c|c|c|}
\hline Code & Interpreted & English & Mean difference & $95 \% \mathrm{Cl}$ & $P$-value \\
\hline Misunderstanding & 30 & 28 & 2 & -36 to 40 & ns \\
\hline Check understanding & 15 & 10 & 5 & -10 to 20 & ns \\
\hline Questions & 101 & 220 & -119 & -231 to -6 & 0.039 \\
\hline Motivation & 83 & 419 & -336 & -565 to -106 & 0.006 \\
\hline Praise & 0 & 17 & -17 & -28.5 to -4.6 & 0.009 \\
\hline Patworld & 110 & 887 & -777 & -158 to -1104 & $<0.001$ \\
\hline 1. Humour & 10 & 207 & -197 & -307 to -86 & 0.001 \\
\hline 2. Lifeworld & 73 & 637 & -564 & -840 to -287 & $<0.001$ \\
\hline 3. Feelings & 26 & 299 & -273 & -456 to -90 & 0.005 \\
\hline 4. Employment & 14 & 100 & -86 & -246 to 75 & ns \\
\hline All clinical & 499 & 1701 & -1202 & -1657 to -748 & $<0.001$ \\
\hline 1. Blood tests & 16 & 58 & -42 & -72 to -10 & 0.011 \\
\hline 2. BP & 21 & 52 & -31 & -79 to 17 & ns \\
\hline 3. Cholesterol & 20 & 42 & -22 & -72 to 30 & ns \\
\hline 4. Exercise & 79 & 139 & -60 & $-172-53$ & ns \\
\hline 5. Eyes & 36 & 48 & -12 & -70 to 46 & ns \\
\hline 6. Feet & 18 & 77 & -59 & -144 to 26 & ns \\
\hline 7. Flu & 14 & 3 & 11 & -5 to 26 & ns \\
\hline 8. Food & 71 & 307 & -236 & -373 to 98 & 0.002 \\
\hline 9. Kidney & 2 & 30 & -28 & -49 to -7 & 0.010 \\
\hline 10. Medications & 144 & 648 & -504 & -757 to -251 & $<0.001$ \\
\hline 11. Smoke & 9 & 63 & -54 & -186 to 78 & ns \\
\hline 12. Sugar and $\mathrm{HbA} 1 \mathrm{c}$ & 180 & 699 & -519 & -831 to -206 & 0.002 \\
\hline 13. Urine test & 14 & 27 & -13 & -46 to 21 & ns \\
\hline 14. Weight & 25 & 157 & -132 & -242 to -22 & 0.021 \\
\hline Medical other & 86 & 397 & -311 & -574 to -46 & 0.023 \\
\hline \multicolumn{6}{|l|}{ Patient's speech only } \\
\hline PClinPar & 55 & 317 & -262 & -438 to -87 & $<0.001$ \\
\hline Epistemic & 46 & 397 & -351 & -514 to -186 & $<0.001$ \\
\hline
\end{tabular}

Interpreted consultations only

Meaning changed

Talk not translated

457

$B P=$ blood pressure. $H b A 1 c=$ glycosylated haemoglobin. $n s=$ not significant. Patworld $=$ patient world . PClinPar $=$ patient clinical parameters. ${ }^{a}$ Numbers show averages per consultation.

overall their talk about 'patient world' was significantly less common in interpreted consultations.

The findings about humour are supported in the Wordsmith analysis shown in Table 5, which also shows that the usage of personal pronouns was different in interpreted consultations. The higher usage of the third person by providers in interpreted consultations is largely because they address the patient through the interpreter rather than directly. Thus, a concordance analysis showed that 'does he' is the most common two-word phrase associated with providers' usage of 'he' in these consultations (33 times), and the most common verbs occurring before 'him' in provider talk in these consultations are 'see', 'ask', 'give', 'tell', and 'help'. Patients are also more likely to use the third person in interpreted consultations.

Tables 3 and 4 also show that substantial amounts of both provider and patient talk contained passages either that were not translated by the interpreter or where the meaning of what was said was changed. Looking at this in terms of the proportion of speech passages ('utterances') involved, $307 / 920$ (33.4\%) utterances made by patients in the 12 interpreted consultations contained some talk that was not translated, and 674/1644 (41.0\%) utterances from the providers contained some talk that was not translated. Interpreters also quite commonly spoke about topics that did not involve an attempted or actual translation of what another speaker had said ("other than translated' speech); 685/2057 (33.3\%) utterances by interpreters involved this kind of material.

\section{DISCUSSION}

\section{Summary}

Interpreted consultations did not last longer than consultations with fluent English speakers. Patients in interpreted consultations spoke less than did Englishspeaking patients, perhaps because interpreters took up some of the time available. However, there was no significant overall difference for nurses' (providers') speech, suggesting that the extra time taken by interpreters affected patients more than nurses.

The reduction in speech affected certain topics more than others. Patients in interpreted consultations were less likely to talk about their own ideas about diabetes and less likely to talk about clinical topics related to diabetes, although this did not hold true for providers' talk about clinical topics. A number of differences reflected the social distance between provider and patient introduced by the lack of a shared language. For example, interpreted consultations were relatively humourless and involved less discussion of the patients' life circumstances ('lifeworld') and less talk about patients' feelings. The Wordsmith findings about personal pronouns indicate that providers rarely addressed nonEnglish-speaking patients directly. Overall, there were fewer questions from patients in interpreted consultations.

These patients were less likely than English-speaking patients to raise issues with providers that appeared unrelated to their diabetes (see differences for the 'medical other' code in Table 3), and it is clear that interpreters may play a role in determining the relevance of passages of this sort (see examples under 'medical other' in Box 1). Interpreters, in fact, had a great deal of latitude in the consultations, 


\section{Table 4. Number of words coded (providers' words only)}

\begin{tabular}{|c|c|c|c|c|c|}
\hline Code & Interpreted & English & Mean difference & $95 \% \mathrm{Cl}$ & $P$-value \\
\hline Misunderstanding & 48 & 43 & 5 & 27 to -45 & ns \\
\hline Check understanding & 10 & 35 & -25 & & \\
\hline Questions & 776 & 1071 & -295 & -754 to 166 & ns \\
\hline Health education & 747 & 735 & 12 & -551 to 575 & ns \\
\hline Motivation & 148 & 299 & 151 & -401 to 99 & ns \\
\hline Praise & 63 & 165 & 102 & -223 to 18 & ns \\
\hline Patworld & 162 & 505 & -343 & -577 to -108 & 0.005 \\
\hline 1. Humour & 38 & 199 & -151 & -216 to -84 & $<0.001$ \\
\hline 2. Lifeworld & 88 & 268 & -180 & -362 to 3 & ns \\
\hline 3. Feelings & 63 & 161 & -98 & -189 to -6 & 0.037 \\
\hline 4. Employment & 0 & 56 & -56 & -165 to 53 & ns \\
\hline All clinical & 2085 & 2536 & -451 & -1617 to 715 & ns \\
\hline 1. Blood tests & 80 & 171 & -91 & -198 to 16 & ns \\
\hline 2. BP & 190 & 142 & 48 & -116 to 211 & ns \\
\hline 3. Cholesterol & 130 & 104 & 26 & -70 to 122 & ns \\
\hline 4. Exercise & 250 & 195 & 55 & -148 to 259 & ns \\
\hline 5. Eyes & 197 & 49 & 148 & -92 to 387 & ns \\
\hline 6. Feet & 83 & 81 & 2 & -109 to 113 & ns \\
\hline 7. Flu & 60 & 19 & 41 & -30 to 112 & ns \\
\hline 8. Food & 308 & 350 & -42 & -318 to 232 & ns \\
\hline 9. Kidney & 64 & 76 & -12 & -91 to 66 & ns \\
\hline 10. Medications & 638 & 1051 & -413 & -1224 to 399 & ns \\
\hline 11. Smoke & 33 & 59 & -26 & -115 to 63 & ns \\
\hline 12. Sugar and $\mathrm{HbA} 1 \mathrm{c}$ & 973 & 1255 & -282 & -1271 to 708 & ns \\
\hline 13. Urine test & 82 & 71 & 11 & -73 to 93 & ns \\
\hline 14. Weight & 162 & 252 & -90 & -309 to 128 & ns \\
\hline Medical other & 128 & 306 & -178 & -366 to 10.3 & ns \\
\hline \multicolumn{6}{|c|}{ Interpreted consultations only } \\
\hline Meaning changed & 222 & & & & \\
\hline Talk not translated & 2225 & & & & \\
\hline
\end{tabular}

$B P=$ blood pressure. $H b A 1 c=$ glycosylated haemoglobin. $n s=$ not significant. Patworld $=$ patient world . ${ }^{a}$ Numbers show averages per consultation. direct observation of interpreted consultations in the UK. This method avoids the problems of relying on self-reported behaviour, which are evident in existing UK studies. ${ }^{710,11}$ The relevance of the study for consultations about other conditions, for settings other than primary care, for other types of provider such as doctors, and for other ethnic groups remains to be established by further research. These routine review consultations usually followed a standard protocol with a predefined agenda and lasted longer than consultations occurring in 10-minute time slots with GPs. In addition, they involved professional interpreters for the most part; communication where family members act in this role may be different. ${ }^{29}$

It is possible that some of the discrepancies in the amount of speech were mitigated by providing more frequent consultations for patients requiring interpreters. Anecdotally, some of the nurses suggested to the researchers that they thought they did this, although there is no other evidence that this occurred. Nor is the success of this strategy known if it did occur; it would be reasonable for repeat visits of this sort to cause some dissatisfaction among patients. It contrasts with recommendations in guides to working with interpreters 27,28 that longer appointments with such patients should be booked.

\section{Comparison with existing literature}

Several differences identified in this study may help explain the dissatisfaction with diabetes care identified in other studies of South Asian groups in the UK.7.10,11 Selfmanagement of diabetes is hard work, involving both cognitive skills and emotional work, arguably best assisted when care providers can connect with the 'lifeworlds' of patients. ${ }^{30}$ It is concerning that there is a relative lack of engagement of the emotional and personal lives of patients in interpreted consultations. Humour, for example, can lighten emotional burdens and promote solidarity but the subtleties of timing and body language it requires are hard to achieve without a shared language. In addition, given the discrepancies in delivery of diabetes-care processes that disadvantage patients from minority ethnic communities, ${ }^{5}$ and the incidence of poorly controlled diabetes in the population of South Asian individuals with diabetes, ${ }^{3}$ it is concerning that patients in interpreted consultations are involved less in discussions of several clinical indicators.

Some of the practices identified in this study may be regarded by one or more 


\section{Funding}

The study was funded by the Perrin bequest associated with Clive Seale's chair when he was at Queen Mary University of London, and by the Foundation for the Sociology of Health and Illness. The Centre for the Study of Migration at Queen Mary provided a small grant for translating the interpreted consultations.

\section{Ethical approval}

The study was approved by London - Surrey Borders Regional Ethics Committee (Ref: 10/ H0806/27).

\section{Provenance}

Freely submitted; externally peer reviewed.

\section{Competing interests}

The authors have declared no competing interests.

\section{Acknowledgements}

We would like to thank the patients, healthcare staff, and interpreters who helped with and participated in the study. The project was advised by a committee including Gillian Hood, Anne Worthington, Annie Cushing, Celia Roberts, Tahseen Chowdhury, Vibhuti Mistry, Fiona Stephenson, Jasmine Begum, Alan Quirk, Judith Green, Trisha Greenhalgh, and Hina Taylor. Students attached to the project were Mayur Murali, Sarah Webb, and Hela Al-Sarraj. Ayan Adan, Abul Hasnath, Sana Malik, and Forhad Hussein translated non-English speech in the interpreted consultations for the researchers. We thank them all for their contributions to the project.

\section{Discuss this article}

Contribute and read comments about this article on the Discussion Forum: http://www.rcgp.org.uk/bjgp-discuss participants as helpful. For example, interpreters answering patients' questions without translating them for providers to answer may think that they are saving valuable time. The finding that interpreters often add material of their own supports a view of them as 'co-diagnosticians', 12,20,26 but the extent to which this is done may be quite reasonable and safe, given the regular experience some of them have in participating in these routine reviews, during which considerable knowledge of diabetes may have accumulated. On the other hand, it is hard for healthcare providers to monitor the quality of interpreters' provision of information to patients if this talk is not translated.

\section{Implications for research and practice}

While this study focused on diabetes, the authors believe many of the challenges identified are generic to interpreted consultations. Recommendations for working with interpreters, ${ }^{27,28}$ if implemented, may go some way towards addressing the challenges that this study has revealed, reducing the social distance of interpreted consultations and helping with patient involvement, which is an essential component of self-management. ${ }^{6}$ These include, for example, recommendations to:
- look at the patient when you are speaking and when the patient is speaking to the interpreter:

- address the patient directly as 'you' rather than addressing the patient in the third person through the interpreter;

- from time to time, summarise what you think the patient is saying and ask for this summary to be translated so that the patient can confirm or deny its accuracy;

- split talk up into small 'chunks' so that it can be translated before delivering the next 'chunk';

- ask the interpreter what was said in the other language, if an extended passage of talk occurs that appears not to have been translated; and

- not engage the interpreter in talk in English without explaining the topic of talk to the patient and translating it if relevant.

However, unless such recommendations are widely implemented and their effectiveness evaluated by well-designed studies, it seems likely that suboptimal communication will occur in consultations where the language of provider and patient is not shared. 


\section{REFERENCES}

1. National Audit Office. The management of adult diabetes services in the NHS London: Department of Health, 2012.

2. Roberts S. Working together for better diabetes care. London: Department of Health, 2007.

3. Dreyer G, Hull S, Aitken Z, et al. The effect of ethnicity on the prevalence of diabetes and associated chronic kidney disease. Q J Med 2009; 102(4): 261-269.

4. Health and Social Care Information Centre. National diabetes audit 2010-2011. Report 1: Care processes and treatment targets. London: Health and Social Care Information Centre, 2012

5. The NHS Information Centre. National diabetes audit 2008-9. London: the NHS Information Centre, 2010.

6. NHS Diabetes. Partners in care: a guide to implementing a care planning approach to diabetes care. London: NHS publications, 2010.

7. Grace C, Begum R, Subhani S, et al. Prevention of type 2 diabetes in British Bangladeshis: qualitative study of community, religious, and professional perspectives. BMJ 2008; 337: a1931.

8. Ipsos/Mori. Awareness of diabetes and Diabetes UK among the general public. London: Diabetes UK, 2007.

9. Lawton J, Ahmad N, Peel E, Hallowell N. Contextualising accounts of illness: notions of responsibility and blame in white and South Asian respondents' accounts of diabetes causation. Sociol Health Illn 2007; 29(6): 891-906.

10. Rhodes P, Nocon A, Wright J. Access to diabetes services: the experiences of Bangladeshi people in Bradford, UK. Ethn Health 2003; 8(3): 171-188.

11. Hawthorne K, Rahman J, Pill R. Working with Bangladeshi patients in Britain: perspectives from primary health care. Fam Pract 2003; 20(2): 185-191.

12. Davidson B. The interpreter as institutional gatekeeper: the social-linguistic role of interpreters in Spanish-English medical discourse. Journal of Sociolinguistics 2000; 4: 379-405.

13. Elderkin-Thompson V, Silver RC, Waitzkin H. When nurses double as interpreters: a study of Spanish-speaking patients in a US primary care setting. Soc Sci Med 2001; 52(9): 1343-1358.

14. Bowler I. They're not the same as us: midwives' stereotypes of South Asian descent maternity patients. Sociol Health Illn 1993; 15: 157-178.

15. Gill PS, Shankar A, Quirke T, Freemantle N. Access to interpreting services in England: secondary analysis of national data. BMC Public Health 2009; 9: 12.

16. Gan S. Lost in translation: how much is translation costing the NHS, and how can we both cut costs and improve service provision? London: 2020Health, 2012.

17. Roberts C, Moss B, Wass V, et al. Misunderstandings: a qualitative study of primary care consultations in multi-lingual settings, and educational implications. Med Educ 2005; 39(5): 465-475.

18. Neal RD, Ali N, Atkin K, et al. Communication between South Asian patients and GPs: comparative study using the Roter Interaction Analysis System. Br J Gen Pract 2006; 56(532): 869-875

19. Schouten BC, Meeuwesen L. Cultural differences in medical communication: a review of the literature. Soc Sci Med 2006; 64(1-3): 21-34.

20. Bolden $\mathrm{G}$. Toward understanding practices of medical interpreting: interpreters involvement in history taking. Discourse Studies 2000; 2: 387-419.

21. Rivadeneyra R, Elderkin-Thompson V, Silver RC, Waitzkin H. Patient centeredness in medical encounters requiring an interpreter. Am J Med 2000; 108(6): 470-474.

22. Aranguri C, Davidson B, Ramirez R. Patterns of communication through interpreters: a detailed sociolinguistic analysis. J Gen Intern Med 2006; 21(6): 623-629

23. Karliner LS, Jacobs EA, Chen AH, Mutha S. Do professional interpreters improve clinical care for patients with limited English proficiency? A systematic review of the literature. Health Serv Res 2007; 42(2): 727-754.

24. Leanza Y, Boivin I, Rosenberg E. Interruptions and resistance: a comparison of medical consultations with family and trained interpreters. Soc Sci Med 2010; 70(12): 1888-1895.

25. Laws MB, Heckscher R, Mayo SJ, et al. A new method for evaluating the quality of medical interpretation. Med Care 2004; 42(1): 71-80.

26. Hsieh E. Interpreters as co-diagnosticians: overlapping roles and services between providers and interpreters. Soc Sci Med 2007; 64(4): 924-937.

27. Kai J, Briddon D, Beavan J. Working with interpreters and advocates. In: Kai J (ed). Valuing diversity: a resource for health professional training to respond to cultural diversity. London: Royal College of General Practitioners, 2006: 201-224.

28. Cushing A. Interpreters in medical consultations. In: Tribe J, Hitesh R (eds). Working with interpreters in mental health. Hove and New York: BrunnerRoutledge, 2003: 30-53.

29. Kai J, Beavan J, Faull C. Challenges of mediated communication, disclosure and patient autonomy in cross-cultural cancer care. Br J Cancer 2011; 105(7): 918-924.

30. Hinder S, Greenhalgh T. 'This does my head in'. Ethnographic study of selfmanagement by people with diabetes. BMC Health Serv Res 2012; 12: 83. 